\title{
LA PUBLICIDAD ANIMADA EN ESPAÑA EN LOS ÚLTIMOS AÑOS (DESDE LOS 90 HASTA NUESTROS DÍAS)
}

\author{
THE ANIMATED ADVERTISING IN SPAIN OF THE LAST \\ YEARS (FROM THE 90'S TO OUR DAYS)
}

\section{AUTOR}

Iván Rodríguez Fernández

Universidad Complutense de Madrid (España)

kirvi_69@hotmail.com

\section{RESUMEN}

Este articulo pretende analizar la relación existente (si es que existe) entre la animación y el mundo publicitario en los últimos años (desde la década de los 90 hasta nuestros días). Para ello analizaremos cual es la tendencia que ha ido desarrollando el mundo de la animación en los últimos años, desde el punto de vista productivo, para saber qué valores estéticos son los predominantes, así como las principales características que definen a esta industria en los últimos años. Posteriormente pondremos en consonancia estos aspectos con las muestras publicitarias que se han ido elaborando a lo largo de estos años, sin olvidarnos de la realidad del mundo publicitario, así como las tendencias del mercado. Nos centraremos para este análisis principalmente en la realidad española, aunque no 
REVISTA DE LA SEECI.

5 RGH XHD HQi QGH



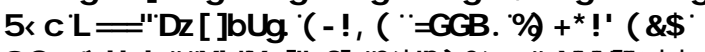

' 2, पKMB]

por ello menospreciaremos otros aspectos, como puede ser el caso de la animación de índole "animesco" y su relación con el mundo publicitario japonés.

\section{PALABRAS CLAVE}

Animación - Publicidad - Anime - Disney - Pixar - Dreamworks - Animación por ordenador - Dibujos animados.

\section{ABSTRACT}

This article tries to analyze the existing relation (if it exists) between animation and the advertising world in the last years (from the decade of the 90 s to the present day). For this reason we will analyze which is the trend that has been developing the animation world during the last years, from the point of view of production (me suena mejor, mira a ver si quiere decir lo mismo), to know what aesthetic values are the predominant ones, as well as the principal characteristics which define this industry in the last years. Later we will put in agreement these aspects with the advertising samples which have been elaborating throughout these years, without forgetting the reality of the advertising world, as well as the trends of the market. We will focus for this analysis principally on the Spanish reality (For this analysis we will focus, principally, on the Spanish reality), though not for this reason we will despise other aspects, as it can be the case of the animation of nature "animesco" ("animesco" type of animation) and its relation with the Japanese advertising world. 
REVISTA DE LA SEECI.

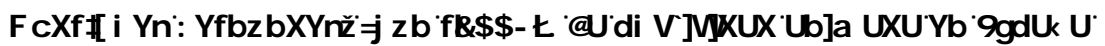

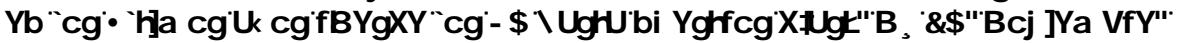

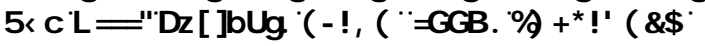

' 2, पKM

\section{KEY WORDS}

Animation - Publicity - Anime - Disney - Pixar - Dreamworks - Computer animation - Cartoons - Advertising.

\section{ÍNDICE}

1. Estado del universo de la animación

1.1 Disney

1.2 Otras productoras

1.3 La animación televisiva

1.4 La animación europea

1.5 La animación por ordenador

1.6 Consecuencias en occidente de esta "nueva" animación

1.7 La animación japonesa

2. Animación publicitaria

2.1 El 3D

2.1.1 Disyuntiva entre animación y efecto

2.2 Simbolismo identificación de marca

2.3 El cambio en la consideración de la animación

2.3.1 El anime en publicidad

2.3.2 Dibujo animado vs Animación por ordenador

2.4 Publicidad y referencias

2.5 Los valores en la publicidad 
REVISTA DE LA SEECI.

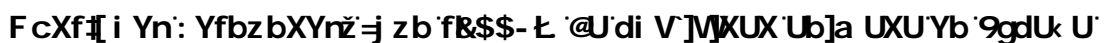

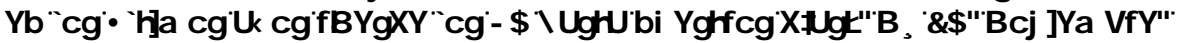

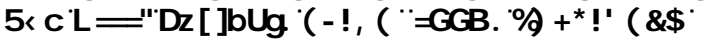

' 2, पKWB

2.6 La imagen

2.6.1 El cartel publicitario

2.6.2 El grafismo

2.7 Las nuevas formas de publicidad

2.7.1 Patrocinio y mecenazgo

2.7.2 Product Placement

2.7.3 Merchaidasing

2.7.4 Otras formas

2.7.5 Internet

2.8 Autopromocionales y cortinillas

3. Conclusiones

4. Bibliografía

\section{Estado del universo de la animación}

Durante los últimos años, la animación ha sufrido un proceso considerable de expansión a nivel mundial.

Desde finales de los años 80 asistimos a una progresiva reinvención de la animación. En ello influenciarán varios factores. 


\subsection{Disney}

Disney, que durante estos primeros años sigue siendo la compañía de referencia, vivirá la denominada segunda edad de oro, esta se iniciará en 1989 con "La Sirenita"1.

La compañía en esta época sufrirá un cambio de dirección y de mentalidad productiva, que le llevará a estrenar una película de animación todos los años². Para poder alcanzar este objetivo, los tiempos de producción se acortan de forma considerable, lo que ayuda a realizar una cantidad considerable de obras en un tiempo relativamente corto.

A pesar de la velocidad de producción de estas obras, la calidad de las mismas no se resiente. La década de los 90 comienza con el éxito, tanto de crítica como de público, de "La bella y la bestia" ${ }^{3}$. Esta será la primera película de animación nominada al Oscar en la categoría de mejor película. Esto es un hecho histórico, que demuestra la renovación en la animación.

El cambio se verá reflejado en las producciones siguientes, como "Aladdin" ${ }^{4} 0$ "El rey león" ${ }^{5}$, todas ellas con un gran éxito de taquilla. Ante este hecho, nuevas compañías quieren participar en el gran pastel de ingresos que supone la animación. La compañía Disney aumenta sus esfuerzos, realizando una gran cantidad de películas, en su mayoría secuelas, enfocadas al medio del video. A

\footnotetext{
${ }^{1}$ MUSKER, JOHN; CLEMENTS, RON; "La Sirenita” TCC "The Little Mermaid", Walt Disney Pictures, 1989.

2 En realidad no se realizan todos los años, aunque ese era el objetivo.

3 TROUSDALE, Gary; WISE, Kirk; "La bella y la bestia" TCC "Beauty and the Beast", Walt Disney, 1991.

4 MUSKER, John; CLEMENTS, Ron; “Aladdin" TCC “Aladino", Walt Disney Pictures, 1992.

${ }^{5}$ MINKOFF, Rob; ALLERS, Roger; "El rey león" TCC “The Lion King”, Walt Disney Pictures, 1994.
} 
REVISTA DE LA SEECI.

5RGH XHD HQi QGH

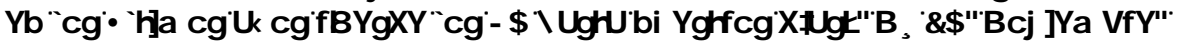

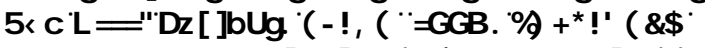

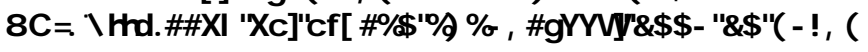

la vez demuestra un aumento considerable del merchandising procedente de sus grandes éxitos, a los cuales les realizan secuelas, juguetes, peluches, muñecos, etc. que se sacan al mercado, incrementados de forma considerable con respecto a la etapa anterior.

Antes de pasar al siguiente punto, es conveniente decir que Disney sigue siendo Disney, pero las películas de esta época reflejan una cierta evolución, consecuencia en gran medida de toda la experiencia adquirida durante estos años. No podemos olvidar que la historia de la animación empieza con Disney, por lo que un completo inmovilismo en sus producciones le imposibilitaría tener éxito en la década de los 90 . En esta época el público ya está habituado a la animación y a muchos de los códigos de Disney.

\subsection{Otras productoras}

Ante el pastel inmenso que se les presentan a las productoras, muchas deciden saltar al ruedo y producir animación, como es el caso de la Universal con las películas de Fievel o En busca del valle encantado. Hay que decir que, gracias al VHS, muchas de estas compañías poseen una pequeña trayectoria en el mundo de la animación. Además de la Universal, es conveniente señalar 20th Century Fox, con "Anastasia", que fue una película ambiciosa con la cual la Fox apuntaba hacia el puesto predominante de Disney de una forma bastante clara. En este panorama se lanza también al ruedo Dreamworks, con películas como "El príncipe de Egipto"7 o "Antz" ${ }^{8}$, en clara competencia con "Bichos, una

\footnotetext{
${ }^{6}$ BLUTH, Don; GOLDMAN, Gary; "Anastasia"; 20th Century Fox, 1997.

${ }^{7}$ WELLS, Simon; HICKNER, Steve; CHAPMAN, Brenda, "El príncipe de Egipto" TCC "The Prince of Egypt"; Dreamworks; 1998.

8 DARNELL, ERIC; JOHNSON. TIM; “Antz”; Dreamworks Pictures, 1998.
} 
REVISTA DE LA SEECI.

5RGH XHD HQi QGH

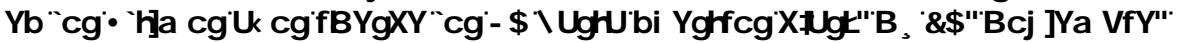

\$XRT , , , आBi J LDV

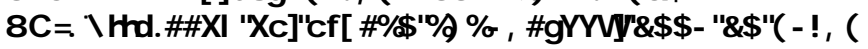

aventura en miniatura" ${ }^{9}$ de Disney, que además es del mismo año. Posiblemente, Dreamworks es una de las nuevas productoras que con más intensidad se mete en el mercado de la animación. Además de estas nuevas productoras, las antiguas siguen produciendo películas de animación, como la Warner con "El gigante de hierro" 10 .

Como es deducible de este panorama, la animación se transforma en uno de los grandes géneros cinematográficos a lo largo de la década de los 90 , y todo ello tendrá un claro reflejo en el inicio del nuevo siglo.

En esta década aparece también Pixar ${ }^{11}$, pero dada su importancia y relevancia, sobre todo a partir del 2000, vamos a olvidarla por un instante para retomarla posteriormente.

Por lo tanto, lo que observamos es una revitalización del mercado cinematográfico de la animación, así como la multiplicación de productoras y de obras. Al mismo tiempo, el mercado del video también aumenta su producción de este tipo de obras, muchas de las cuales, se producen a la sombra de los grandes éxitos cinematográficos.

\subsection{La animación televisiva}

El éxito de estas obras, no solo se cierra en el cine y video, sino que también llega a la televisión. Para ella se producirán series de las más exitosas películas

\footnotetext{
9 LASSETER, John; STANTON, Andrew; "Bichos, una aventura en miniatura" TCC "A Bug's Life"; Walt Disney Pictures; 1998.

${ }^{10}$ BIRD, Brad; "El gigante de hierro" TCC “The Iron Giant”; Warner Bros. Pictures, 1999.

11 No aparece en el 2000, sino que ya en 1986 realiza su primer cortometraje, "Luxo Jr.". Pero será en esta década cuando se transforme en una gran compañía.
} 
REVISTA DE LA SEECI.

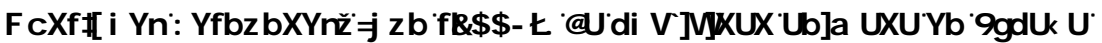

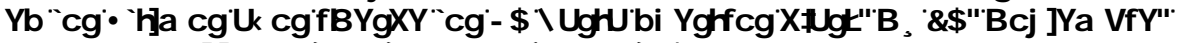

$\$ \times R[$, , , आBi J LDV

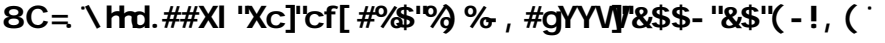

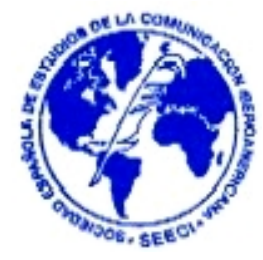

de animación de las diversas compañías. Pero no solo es un aspecto que afectará exclusivamente a las películas de animación, sino que muchos éxitos cinematográficos contarán con una serie de animación, como podría ser el caso de "La Máscara", cuya película es de 1994 y la serie de animación de un año posterior $^{12}$.

Estos hechos vienen a reflejar, por un lado una mayor conexión entre los diferentes medios, por otro el poder de crear un bucle continuo de promoción entre los diferentes medios, que a su vez en muchos casos puede ayudar para vender todos los productos que a este tipo de producciones están asociados, y por último una nueva apuesta por la animación como estilo de producción.

Esta nueva apuesta, viene reflejada en la gran producción de series de animación que se realizan durante estos años, muchas de las cuales se crean como consecuencia de la gran expansión que está sufriendo la animación.

Uno de los aspectos más importantes de la animación televisiva de estos años, es la aparición de las series de orden sarcástico crítico, como "The Simpson", "Padre de familia"13 o "South parck"14. Estas series lo que vienen a demostrar, es la evolución que se produce en la concepción de la animación en los 70, con la animación para adultos.

\footnotetext{
12 STELlino, Greg; "La Máscara” TCC "The Mask: The Animated Series”; Dark Horse Entertainment, Film Roman Productions, New Line Cinema, Sunbow Entertainment; 1995.

13 MACFARLANE, Seth; "Padre de familia" TCC "Family Guy"; 20th Century Fox Television; 1999.

${ }^{14}$ PARKER, Trey; STONE, Matt; "South Park'; Comedy Partners; 1997
} 
REVISTA DE LA SEECI.

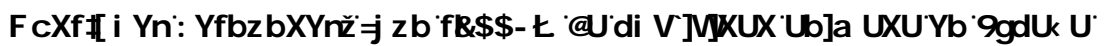

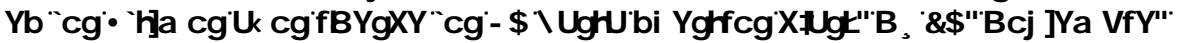

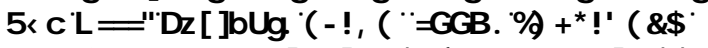

' 2, पKW

\subsection{La animación europea}

En Europa, también se produce un aumento de la producción, tanto de largometrajes como de las series de televisión ${ }^{15}$. En Gran Bretaña por ejemplo, tiene una gran importancia la técnica de Stop Motion, con obras como "Chicken Run"16.

La verdad es que, a la sombra del éxito que se produce con la animación, sobre todo a partir del 2000, la animación europea dedicada al cine, así como a la televisión, aumenta.

\subsection{La animación por ordenador}

En el 2000 asistimos a un cambio de tendencia. Se produce el boom de la animación por ordenador, en detrimento de la animación tradicional. Esta nueva vía, se inicia tímidamente tras el éxito de "Toy Story"17. Los principales éxitos, en una primera instancia, vendrán de la mano del acuerdo entre Disney y Pixar.

\footnotetext{
${ }^{15}$ El aspecto de las series de televisión ya empezó en la etapa anterior.

16 PARK, Nick; LORD, Peter; "Chicken Run"; DreamWorks SKG; Aardman Animations; Pathé Pictures International, 2000.

${ }^{17}$ LASSETER, John; “Toy Story”; Walt Disney Pictures, Pixar Animation Studios; 1995.
} 
REVISTA DE LA SEECI.

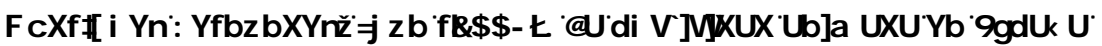

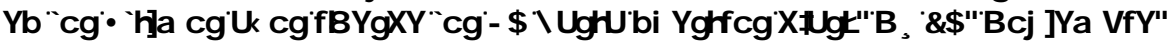

\$ XRI , , , आBi J LDV

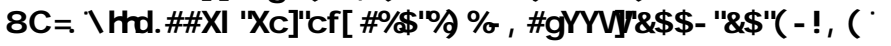

En el nuevo siglo producirán éxitos como "Mounstros S.A." ${ }^{18}$, "Buscando a Nemo"19 o "Los increíbles" ${ }^{\prime 20}$. Los buenos resultados de la unión de ambas compañías, llevará a Disney a comprar Pixar en 2006. Tras la compra Pixar, esta seguirá realizando obras para Disney como “Wall-e"21.

Pero la animación por ordenador no es solamente terreno de Disney, sino que el resto de compañías también participan, como la Fox con su exitosa serie "Ice age"22, o la Dreamworks con otra serie famosa como es "Shrek"23. "Shrek", además intenta destruir los mitos de la animación correspondientes a la primera época dorada de Disney, reflejando al mismo tiempo la crítica y competencia entre ambas compañías, así como el cambio de mentalidad en la concepción de la animación.

\subsection{Consecuencias en occidente de esta "nueva" animación}

Este aumento de la producción, cambio de mentalidad, aumento de la calidad de las obras, etc. conducirá a la creación en los Oscar de la categoría de Mejor película de animación ${ }^{24}$. Tras los Oscar muchos otros premios cinematográficos

18 DOCTER, Pete; SILVERMAN, David; UNKRICH, Lee; "Mounstros S.A." TCC "Monsters Inc."; Walt Disney Pictures, Pixar Animation Studios; 2001.

19 UNKRICH, Lee; STANTON, Andrew, "Buscando a Nemo" TCC "Finding Nemo"; Walt Disney Pictures, Pixar Animation Studios; 2003.

${ }^{20}$ BIRD, Brad; "Los increíbles" TCC "The Incredibles"; Walt Disney Pictures, Pixar Animation Studios; 2004.

${ }^{21}$ STANTON, Andrew; “Wall-e" ; Walt Disney Pictures, Pixar Animation Studios; 2008.

22 Hasta el momento son 3 películas.

${ }^{23}$ Ya se está preparando el cuarto largometraje, al que además hay que sumar un cortometraje para la televisión, por lo que ya son 5 las obras de esta serie.

${ }^{24}$ La primera vez que se da el premio es en el 2001 (ceremonia que se celebra en el 2002). 
REVISTA DE LA SEECI.

5 RGH XHD HQi QGH

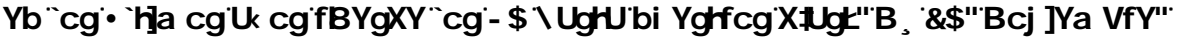

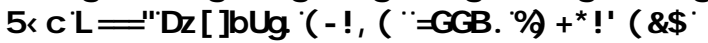

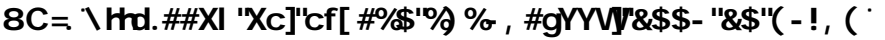

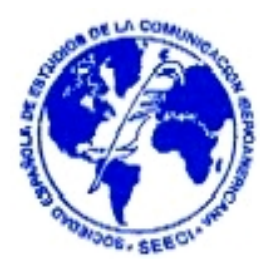

la incluirán, como los Bafta del Reino Unido. Estos premios nacionales, responden también al aumento de la producción de este tipo de obras en los diferentes países del mundo, además del creciente interés que estas generan.

Pero el aspecto más importante, es que la animación empezará a dejar de ser un género exclusivo para niños, apareciendo la animación para adultos ${ }^{25}$ e incluso produciéndose una cierta adaptación de los productos enfocados para niños, dejando en muchos de los casos de enfocar exclusivamente hacía un público infantil. Actualmente, la animación ya no es un género solo para niños, sino que es un género, en términos generales, apto para todos los públicos.

A lo que estamos asistiendo es a una evolución dentro del propio género. Y no solo dentro de la industria, también de las consideraciones del público. Todo ello conduce a un periodo, en el cual la animación es posiblemente el género más vivo del cine, además de la vitalidad que posee en televisión.

Las empresas, nuevamente recurren a la animación como estilo para sus comerciales, produciéndose un aumento de los spots que se crean bajo esta forma. Es cierto, que hay una diferencia con respecto a los periodos anteriores, y es que ahora la animación 3D (o por ordenador) es la estrella, además de en la que se fundamentan muchos de estos productos, aunque sería más conveniente hablar de la animación como efecto, que como elemento básico de la obra.

Nuevamente estamos en una época dorada de la animación. En este periodo se da en tres vertientes: cine, televisión y publicidad. Ante este éxito mundial de la animación, a lo que asistimos es a una sobrexplotación de la misma y a la multiplicación de los elementos de animación dentro de la sociedad.

${ }^{25}$ Aunque ya existían productos de forma previa. 
REVISTA DE LA SEECI.

5RGH XHD HQi QGH

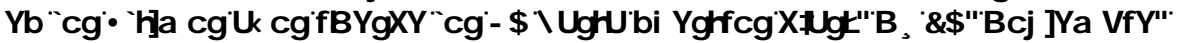

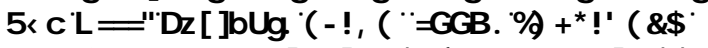

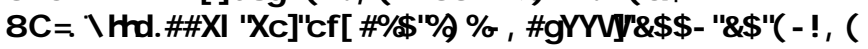

\subsection{La animación japonesa}

La animación japonesa produce su ingreso en occidente en la década de los 70, en muchos casos a través de las coproducciones, pero poco a poco se irán instaurando series realizadas propiamente en Japón, algunas de las cuales gozarán de un considerable éxito, como es el caso de todas las series de "Bola de Dragón" 26 .

"Dragon Ball" es una serie muy importante para la historia del anime, pero lo que producirá el cambio será: por un lado Miyazaki con "El viaje de Chihiro"27, y por otro, la serie "Naruto"28 ya en la década del 2000. A finales de los años 90 el universo "otaku" empieza a tomar forma con series como "Evangelion"29, entre otras. De todos modos, no podemos considerar que antes del 2000 se produzca el verdadero, y gran impacto del anime en la sociedad occidental.

La importancia que estas obras irán adquiriendo se reflejará en la exportación del anime a otros sistemas productivos, entre ellos el español, el cual producirá incluso una película de estilo animesco ${ }^{30}$. Esto viene a reflejar el gusto de la sociedad hacia esta forma estilística.

Hay que decir, que en el caso del anime, el medio con mayor importancia es internet, como consecuencia de la legalidad japonesa, la cual permite la

\footnotetext{
${ }^{26}$ Señalo que la serie consta de tres partes: Bola de dragón, Bola de dragón Z, y Dragon Ball GT.

27 MIYAZAKI, Hayao; "El viaje de Chihiro" TCC "Sen to Chihiro no kamikakush" TCC "Spirited Away", Studio Ghibli, Tokuma Shoten, Dentsu, Walt Disney Pictures; 2001.

28 DATE, Hayato; NIMOY, Jeff; "Naruto”; Toei Animation; 2002.

${ }^{29}$ ANNO, Hideaki; "Neon Genesis Evangelion"; Gainax, TV Tokyo, NAS; 1995.

30 2Gisaku"
} 
REVISTA DE LA SEECI.

5RGH XHD HQi QGH

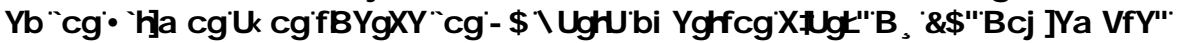

\$XRT , , , आBi J LDV

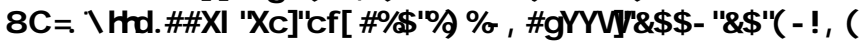

descarga de los productos audiovisuales no licenciados en los diversos países ${ }^{31}$. A esto hay que sumar el tiempo que se necesita para adaptar las obras del japonés a las diversas lenguas nacionales, así como los pésimos doblajes, y por último la censura que en muchos casos sufren estos productos.

Para combatir contra internet, canales como Cartoon Network ha llegado a emitir la serie "D. Gray Man"32 en japonés con subtítulos.

Aún es pronto para saber si el anime tendrá su reflejo en el mundo publicitario, aunque dadas las características del producto de anime, será difícil su cabida dentro de los productos no enfocados a un target muy determinado. Pero de todos modos, actualmente es una de las animaciones con más éxito de todas. Es muy posible que en grafismo, y carteles publicitarios, si tenga una cierta importancia, o esto es lo que nos da a entender la situación actual.

Es importante señalar, el gran merchandasing que este tipo de producciones puede general. Los juguetes de series como "Dragon Ball”, están presentes en las jugueterías, además del gran mercado del videojuego, el cual es uno de los sectores más importantes actualmente.

\section{Animación publicitaria}

Durante este periodo, se produce un renacer del mundo de la animación en el sector publicitario. En realidad, no es muy correcto hablar de renacer, ya que

\footnotetext{
31 Sentencia del tribunal de Japón, FPC, No. 0690, Copyright 2006 Centro de Prensa Extranjera / Japón. Publicación 15 de Diciembre 2006.

32 NEBESHIMA, Osamu; KURIMOTO, Hiroshi; HARADA, Nana; “D. Gray Man”; TMS Entertainment; 2006.
} 
REVISTA DE LA SEECI.

5RGH XHD HQi QGH

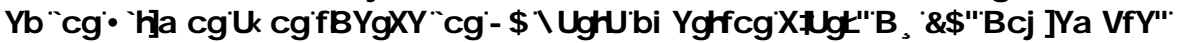



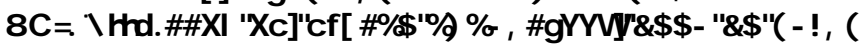

más que producciones íntegramente animadas, se produce un híbrido entre animación e imagen real.

Durante estos años, se produce una serie de avances en la tecnología de la animación, sobretodo en la animación creada por ordenador, que permite que la animación se incluya en la publicidad con una mayor facilidad.

Sin duda, la técnica y el gran salto que da esta, será uno de los factores que contribuyan a una mayor participación de la animación en la publicidad. Llegados a este punto, quiero hacer referencia a las palabras de María Luisa Martínez Barnuevo en referencia a la animación 3D. "EI 3D ha supuesto una nueva estética más fresca y más cercana a la realidad [...]"(Martinez Barnuevo, pág 63$)^{33}$.

Este fragmento es muy representativo. La nueva tecnología permite que la animación empiece a no ser percibida como animación, sino más bien como un elemento más de realidad que es introducido en los spots. Esta es, posiblemente, la utilización más habitual de la animación por el mundo publicitario.

\subsection{El 3D}

El 3D, o mejor dicho, la animación por ordenador, será la animación predominante en estos años ${ }^{34}$. En el sector europeo, España será el primer país

\footnotetext{
33 MARTÍNEZ BARNUEVO, María Luisa; "El largometraje de animación español: análisis y evaluación."; Ediciones y publicaciones Autor S.R.L., Madrid. Pág 63.

34 MARTÍNEZ BARNUEVO, María Luisa; "El largometraje de animación español: análisis y evaluación."; Ediciones y publicaciones Autor S.R.L., Madrid. Pág 186 - 192 y 232, se puede observar como la animación es un sector en auge desde hace 15 años.
} 
REVISTA DE LA SEECI.

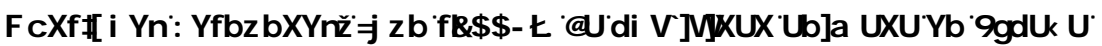

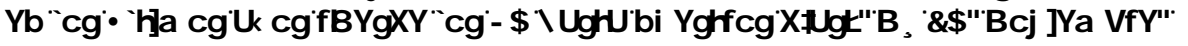

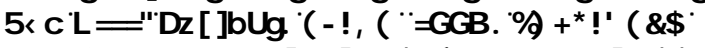

' 2, पKMB]

en realizar largometrajes bajo está técnica. Podemos llegar más lejos, ya que los dos primeros largometrajes europeos bajo esta técnica son españoles ${ }^{35}$.

Pero en lo que se refiere al mundo publicitario, la animación ya no es el motivo creador, sino que es utilizada como efecto para animar a ciertos elementos de la producción. La unión de ambos mundos, el real y el animado, ya se había llevado a cabo bajo la técnica de los dibujos animados en varias producciones, aunque el éxito en este aspecto llegará con "Mary Poppins"36, y aumentaría sus posibilidades con obras como “¿Quién engaño a Roger Rabbit?" ${ }^{37}$. Hay más ejemplo de esta relación, pero por término general siempre se marcaba una clara diferencia entre el mundo animado y el de imagen real. Al primero le tocaba ser alocado, divertido, etc. mientras que el de imagen real debía mantener una cierta compostura, que a su vez nos ayudara a reconocer que este era el mundo real.

Así, la animación pasará a formar parte de los spots de forma común, aunque eso sí, no como piezas integras de animación, sino que será una mezcla entre efectos y personajes animados. Quiero decir, en la mayoría de los casos la publicidad recurrirá a la animación para generar una serie de efectos para su spot. Esto también sucede en las películas actuales, poco a poco la animación, entendida como efectos especiales, gana fuerza.

Esta primera consideración respecto a la animación, es consecuencia directa de las mejoras técnicas, y responde más a aspecto técnicos que a consideraciones animadas. Siempre ha existido la disyuntiva entre animación (Cohl) y efectos (Méliès o Segundo de Chomón). Cada vez es más complicado separar ambos

\footnotetext{
35 “Megasónicos" es la primera y "El ladrón de sueños" es la segunda.

${ }^{36}$ STEVENSON, Robert; “Mary Poppins"; Walt Disney, 1964.

37 ZEMECKIS, Robert; “¿Quién engaño a Roger Rabbit?”TCC “Who framed Roger Rabbit?”; Walt Disney Pictures; 1988.
} 
REVISTA DE LA SEECI.

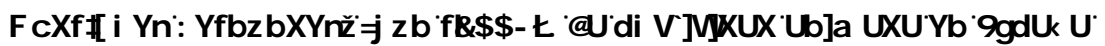

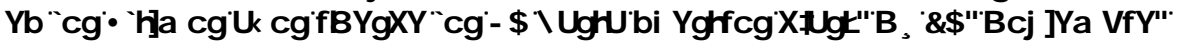

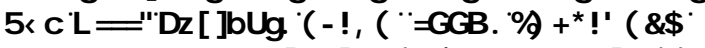

' 2, पKW

universos, y con las diferentes definiciones de animación existentes, no podemos realizar una conclusión clara a este respecto ${ }^{38}$.

\subsubsection{Disyuntiva entre animación y efecto}

No vamos a entrar a definir animación, ya que posiblemente definir qué es animación y qué no lo es supondría un trabajo integro independiente. Solo me dispongo a realizar los matices que he expresado, dejando a voluntad del espectador la elección.

Un ejemplo de spot que realiza animación como efecto es el de "Repsol", del año 1994, donde la animación es empleada para realizar una construcción de una plataforma petrolífera en el mar.

O el anuncio de Pepsi, de 1995 que podemos titular "Cambia el guión", en el que se recurre a la animación para hacer el efecto de los niños llorando.

Por otro lado, tenemos los spots que recurren a la animación para crear personajes, o incluso para animar el logotipo o el símbolo de la empresa, como puede ser el caso de la bayeta ballerina. Esta animación, normalmente en 3D con fondos y personajes en imagen real, supone otorgar vida al símbolo de la empresa. Esto puede estar muy en consonancia con la ideología de la publicidad de estos años.

\footnotetext{
38 En el libro de MARTÍNEZ BARNUEVO, María Luisa: El largometraje de animación español: análisis y evaluación.; Ediciones y publicaciones Autor S.R.L., Madrid, podemos encontrar diversas definiciones además de una consideración de lo que es animación.
} 
REVISTA DE LA SEECI.

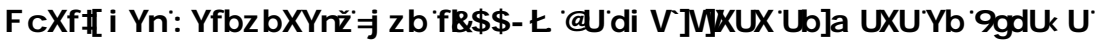

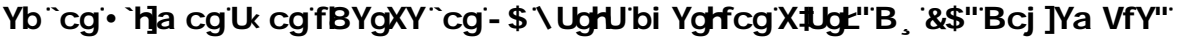

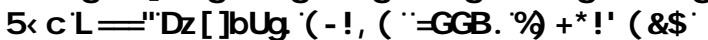

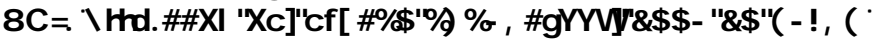

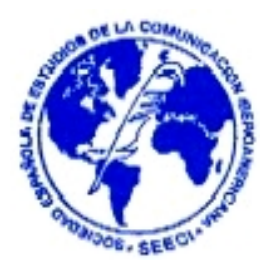

\subsection{Símbolos e identificación de marca.}

Actualmente, se pretende revertir a las empresas de una cierta personalidad y valores. Ya no se vende un producto, sino que se prefiere crear una imagen de marca. Los logotipos, símbolos y/o identificaciones de las empresas, tienen que representar esos valores.

Este aspecto, lo podemos observar en el "Mayordomo de Teen", el cual según han pasado los años se ha ido adecuando a los principios imperantes en la sociedad. El payaso de "Mcdonald" es otro ejemplo de símbolo que representa a una empresa. La iconografía es un elemento que ayuda a reconocer ciertas marcas, como por ejemplo el vaquero con su caballo y Malboro.

Los símbolos tienen, no solo que identificarse con una empresa y/o marca, sino que tiene que representar los valores de esa empresa.

Ejemplo de esta iconografía animada puede ser el monigote de "Amena" o el de "7up", con un razonable parecido entre ambos. El caso del muñeco de "7up", podemos observar por su vestimenta, deportivas, ropa amplia, pantalones cortos, etc. que es un producto que se enfoca a un público joven y moderno.

Estos personajes son provistos de una personalidad y concepción que ayude a los posibles consumidores a identificarse con ellos. La proyección es uno de los principios básicos, al mismo tiempo que ayudan a mostrar cómo es una cierta empresa, qué valores posee, su ideología, etc. Este tipo de emblemas, pasan a ser la representación de la marca y/o producto, por lo que es muy importante su creación gráfica y su estética y personalidad.

Este tipo de aspectos ya se vienen reflejando en las producciones cinematográficas de animación, donde empieza a existir una mayor preocupación por la construcción de los personajes, por su historia, etc. Todo 
REVISTA DE LA SEECI.

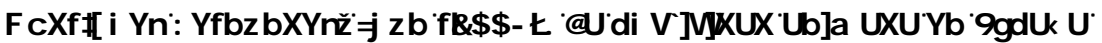

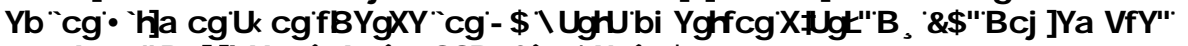

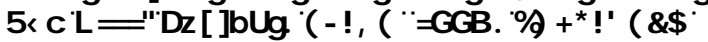

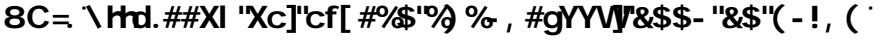

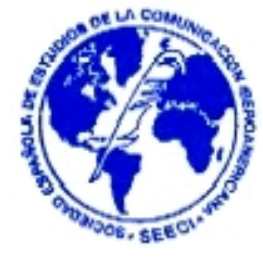

esto se verá reflejado en la mejora de la calidad de los productos. Esta mayor elaboración contribuirá al cambio de concepción de la animación, la cual poco a poco dejará de ser considerada un producto exclusivamente infantil.

\subsection{El cambio en la consideración de la animación}

El cambio de consideración permite ampliar el target de este tipo de productos. Pixar es un referente sin duda para todo este periodo, primero por su "Toy Story", que es una película clave de la historia de la animación, y por su influenciará a toda la producción posterior de 3D. "Toy Story" supuso la demostración de hasta donde se podía llegar con un ordenador. Desde ésta, la animación 3D no ha dejado de crecer. Pero además Pixar que se asocia a la Disney para producir una serie de películas, supone un cambio de discurso, y esto sucede desde dentro de la gran empresa de la animación.

El cambio de discurso ya venía reflejándose en series como "The Simpson" o "South Park", como ya he expresado anteriormente. Estas series, suponen una vuelta a aquella animación crítica y sarcástica de los inicios del cine, de aquellas primeras animaciones que tanto bebían de las tiras cómicas/sarcásticas de los periódicos. Estas producciones vienen a demostrar que la animación puede cubrirse de sarcasmo, de crítica social, y de mucho humor. Estas obras han demostrado que la animación puede ser realista, que no se trata de un aspecto técnico, sino en contenido, en mensaje. La animación nuevamente es un género que puede ser realista.

Pero no solo el cambio de discurso contribuye a esta variación de consideración. A esto tenemos que sumar, la perdida por parte de la televisión de su posición como medio predominante. 
REVISTA DE LA SEECI.

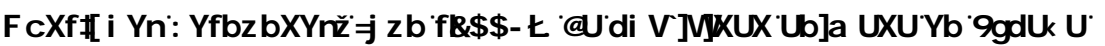

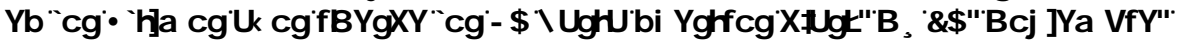

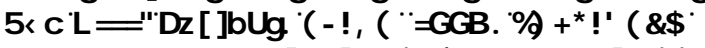

' 2,

Una de las características de esta época es la diversificación de los medios, entre los que tenemos que destacar internet. Al mismo tiempo, la televisión va perdiendo su poder, y con esta pérdida aquella consideración de realidad que había impuesto la televisión, se desdibuja ${ }^{39}$. Las personas se han habituado tanto al mensaje televisivo, como a su forma, por lo que aparecen voces contrarias. Poco a poco la televisión empieza a perder su poder. A esto sumemos que la atomización de la sociedad se radicaliza en estos años, por lo que los grandes medios de masa pierden fuerza a favor de aquellos más específicos.

Esto no solamente afectará a la animación, sino que también el mundo publicitario también se verá afectado. Como consecuencia de esta pérdida de poder de la televisión (además de la habituación por parte del espectador a las formas publicitarias), las empresas tienen que recurrir a nuevas formas de promoción, como por ejemplo las relaciones públicas, la publicidad en el lugar de venta, etc. Esto también tendrá su reflejo dentro de la propia empresa publicitaria, la cual se transformará para adaptarse a las nuevas exigencias ${ }^{40}$. Posteriormente veremos algunas nuevas formas de publicidad y su relación con el mundo de la animación.

Volviendo al tema del cambio de consideración en la animación como producto exclusivamente infantil. Este aspecto también se ve reforzado por la llegada de

\footnotetext{
39 Tras la implantación de la televisión la consideración de lo inmediato y la imagen real como la "realidad" se impone sobre otras formas de realidad. Durante la segunda guerra mundial, la animación es considerada un género realista, y crítico con la sociedad, de ahí que durante este periodo se realicen muchas obras de propaganda siguiendo este formato. Pero tras la implantación de la televisión como medio predominante, la consideración de "realidad" cambia a una más acorde con este medio.

40 EGUIZÁBAL MAZA, Raúl: Industrias de la conciencia. Una historia social de la publicidad en España (1975 - 2009); Ediciones Península; Barcelona 2009. Págs. 279 - 308. En este capítulo analiza estos cambio en la empresa publicitaria, algunas nuevas formas de venta, etc.
} 
REVISTA DE LA SEECI.

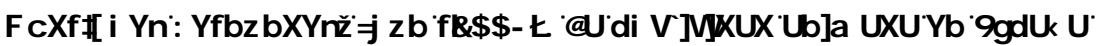

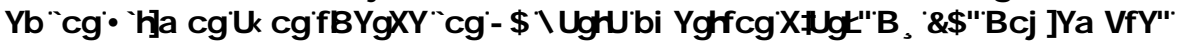

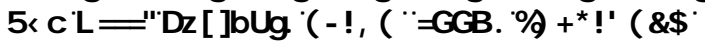

' 2, पKMB

productos japoneses, cuyo público objetivo es adulto. Estos productos en un primer momento estás reservados a un pequeño grupo, ya que no cuentan con un gran apoyo por parte de las televisiones, sobre todo los productos para adultos. Ante esto podemos decir que internet será el gran medio de difusión, y tras el éxito de algunos productos en la red, las televisiones decidirán apostar por ellos, produciendo que su difusión sea aún mayor.

\subsubsection{El anime en publicidad}

En el caso concreto del anime, la consideración de producto exclusivamente infantil no ha existido entre las últimas generaciones, por lo que todo este proceso en Japón no se ha dado. Esto posiblemente ha ayudado a que el estudio Ghibli, que es la productora de Miyazaki o Takahata, haya participado en el mundo publicitario. Ejemplos pueden ser los sptos de "Umacha", "Online shopping mal Shop-One" de 2000, la del periódico "Yomiuri", "Risona Bank" de 2003, los promocionales del museo Ghibli de 2001, los productos de sus películas como "Sen to Chihiro" de 2001, y por supuesto publicidad de patrocinio, como los spots que realiza para patrocinar "The Cat Returns" para el curry "Hausu". Además de spots, ya independientes, que también le realiza para la compañía Hausu. Sin pararnos a analizar estas producciones, hay que mencionar que todas ellas están realizadas en dibujos animados.

Este aspecto es importante, ya que en occidente el dibujo animado en publicidad ha casi desaparecido en favor de la animación por ordenador. 
REVISTA DE LA SEECI.

5RGH XHD HQi QGH

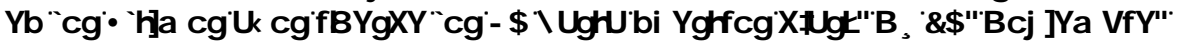



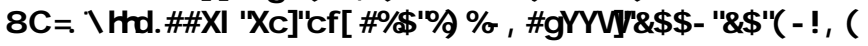

\subsubsection{Dibujo animado vs. Animación por ordenador.}

Como comentaba, en occidente el dibujo animado ha ido desapareciendo, esto sería consecuencia de varios factores. Por un lado, que la animación por ordenador produce un realismo estético que los dibujos animados no pueden reproducir. Por otro, que los productos en occidente no son construidos bajo la estética de la animación, y por lo tanto, es más fácil integrar la animación por ordenador con la imagen real, salvo que queramos realizar una marcada diferenciación entre ambos aspectos, pero esto tampoco es un problema para la animación por ordenador.

Un ejemplo de esta diferenciación lo podemos encontrar en los anuncios de radical. Aquí se recrea el mundo del comic, mezclado con tendencias de cine negro. Es un anuncio muy juvenil, donde la estética es irreal e idealizada, mostrando mucho los arquetipos de un género. Todo ello mezclado con el humor.

El humor es un aspecto muy importante en la publicidad, sobre todo la de los años 90'. La animación occidental es claramente humorística, por lo que puede ir en sintonía con este aspecto, contribuyendo a su aceptación. Por el contrario, el anime (mayoritariamente japonés) no es claramente humorístico, y se pueden dar diversos estilos dentro de su producción. Este aspecto se observa en las producciones mencionadas en el apartado anterior, donde algunas recurren a la tradición, la añoranza, etc. 
REVISTA DE LA SEECI.

5RGH XHD HQi QGH

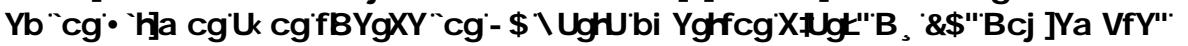

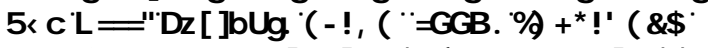

' 2, पKW

\subsection{Publicidad y referencias}

La relación de la publicidad y el cine ya se ha mostrado durante bastante tiempo, y en el caso de muchas producciones japonesas del estudio Ghibli, esto es perceptible. En occidente también se da este tipo de relación, como el caso del anuncio del Galoper de 1997, donde aparece un extraterrestre creado por animación, y con una clara referencia a la película "Los hombres de negro". Pero en el caso de este anuncio, las referencias a otros medios no se quedan ahí, sino que también se realizan al mundo de la televisión, o más concretamente al programa "Lo que necesitas es amor" y a su presentados Jesús Puente, etc.

Más recientemente, tenemos el ejemplo de Clio donde el coche se transforma en una especie de robot. La referencia de este anuncio, no es tanto la película de Hollywood "Transformers", como la serie homónima en la que está basada (y de origen japonés). Obviamente, el éxito de la película pudo contribuir al spot, pero las referencias a la serie mítica de los $80^{\prime}$ son más visibles ${ }^{41}$. No tenemos que olvidar, que la película es de 2007, y referencias a esta serie se pueden observar de forma previa.

Posiblemente, si el anuncio se hubiese realizado en Japón, este respetaría su concepción en animación, no porque en occidente no se respete la estética de las películas o series en las que se pueden basar los spots, sino por lo que la animación representa en sí. En el respeto de la estética, podemos encontrar el anuncio de Audi A4 de 1998. Este anuncio hace referencia a la película "King Kong", y además de la estética en cuanto al colorido, el gorila mantiene una estética totalmente de stop motion, como en la película original. El problema,

${ }^{41}$ Puntualizar que primero fue serie y luego juguete, aunque ambos productos son de 1984. 
REVISTA DE LA SEECI.

5RGH XHD HQi QGH

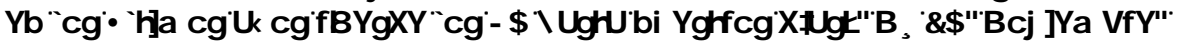

\$XRT , , , आBi J LDV

' 2, पKM

en cuanto a la animación en dibujos animados, reside en su tradicionalidad y lo antiguo de la misma.

\subsection{Los valores en la publicidad}

La publicidad en esta época promueve una serie de valores, como son el cuerpo perfecto, la salud, la ecología ${ }^{42}$, la conciencia social y la tecnología ${ }^{43}$. La tecnología, la cual está en constante evolución, nos proporciona el futuro. Esta visión de futuro en occidente, está más acorde con la animación por ordenador $3 \mathrm{D}$, en oposición al tradicional y anticuado 2D. Anteriormente, he mencionado que la publicidad en este periodo quiere crear una imagen de marca, este aspecto se vería perjudicado por una animación en dibujos animados. En Japón, por el contrario, donde llevan realizando desde hace varios años productos de corte futurista dentro del anime, los dibujos animados pueden representar el futuro.

El anuncio de Golf de 1994 puede ser un buen ejemplo, en el nos remiten a la interactividad, aspecto inexistente en aquellos años, aunque se empezaba a hablar de ella, por lo que se veía como el poder de la ciencia, algo nuevo, futurista, etc.

Por consiguiente, la elección de un estilo de animación u otro está muy en consonancia con la imagen que la empresa pretende transmitir. La animación por ordenador representa una animación tecnológica, mientras que los

\footnotetext{
42 EGUIZÁBAL MAZA, Raúl: Industrias de la conciencia. Una historia social de la publicidad en España (1975 - 2009); Ediciones Península; Barcelona 2009. Págs. 444 - 452

43 EGUIZÁBAL MAZA, Raúl: Industrias de la conciencia. Una historia social de la publicidad en España (1975 - 2009); Ediciones Península; Barcelona 2009. Págs. 340 - 348; 373 - 375 y 491 - 496.
} 
REVISTA DE LA SEECI.

5RGH XHD HOD QGH

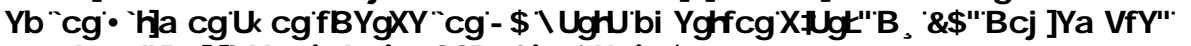

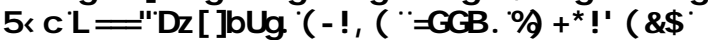

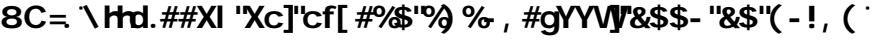

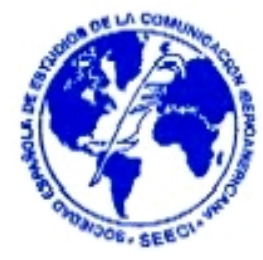

tradicionales dibujos animados representan un trabajo más manual. Un spot que puede representar este concepto es el de "Evax" de 1997, donde los decorados son pintados, representando una idealización del mundo, un mundo seguro, cálido, etc. En este anuncio se recurre a la estética de dibujo pintado en los fondos, ya que de esta forma se transmiten una serie de ideas que de otra forma sería más complejo transmitir.

\subsection{La imagen}

La imagen durante esta época adquirirá una gran fuerza. La imagen en los años $80^{\prime}$ era una imagen bella, que pretendía seducir al espectador por la belleza de la misma. La imagen aquí adquiere una mayor significación, no se trata de seducir al espectador, lo que se pretende es transmitirle una serie de información a través de las imágenes. La imagen se compone de una forma más exhaustiva. Es conveniente no obstante, señalar que estos aspectos ya se venían reflejando en años anteriores, por lo que no son propiamente de esta época. Pero sin duda es en estos años donde la construcción de imagen corporativa tendrá más importancia.

\subsubsection{El cartel publicitario}

Posiblemente sea el cartel publicitario aquel que refleje mejor este poder de la imagen, actualmente los carteles están cargados de iconografía, de referencias y incluso de provocación, se trata de provocar al consumidor. Esta provocación también es visible en algunos anuncios audiovisuales, sobre todo los relacionados con los perfumes. 


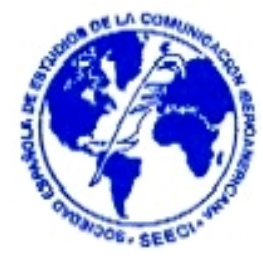

\subsubsection{El grafismo}

Este poder de la imagen, no quiere decir que la palabra desaparezca, como por ejemplo en el anuncio de Volvo de 1992, donde el grafismo animado es lo que compone el spot. Estas frases realizan las acciones que en ellas están escritas, por lo que se produce un doble mensaje. Las frases son en referencia a la seguridad vial. Esto acentúa la preocupación de Volvo en este aspecto, además de mostrarnos que la compañía piensa en esta seguridad a la hora de realizar sus productos. Otro ejemplo de esto es el anuncio de Vips de 1993, en el cual la grafía remite a una letra de niño, que va en consonancia con la voz en off. Concluyendo este aspecto de la imagen, frente a la imagen seductora de los 80', ahora tenemos una imagen simbólica.

\subsection{Nuevas formas de publicidad}

Anteriormente he mencionado que aparecen nuevas formas de publicidad.

\subsubsection{Patrocinio y mecenazgo}

Una de ellas es el patrocinio y mecenazgo. Esto quiere decir que determinados productos son "ofrecidos" por una determinada marca y/o producto. Esto es muy visible por ejemplo en determinadas competiciones deportivas, las cuales son patrocinadas por ciertas empresas. El patrocinio sirve para mostrar el interés por la sociedad por parte de las diversas empresas, además de crear una cierta imagen de marca. Se trata de una publicidad que no es considerada por el consumidor como publicidad. En el caso de la animación, los patrocinios de las diversas series están al orden del día. 
REVISTA DE LA SEECI.

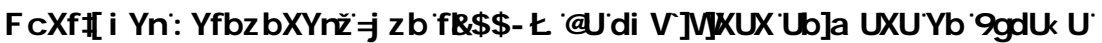

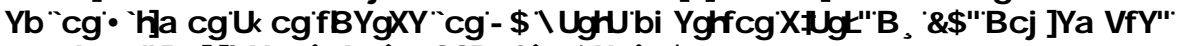

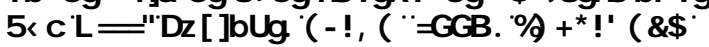

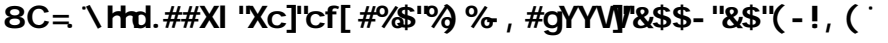

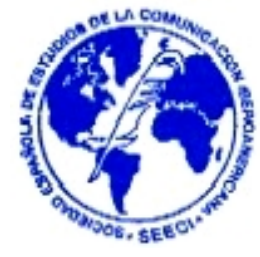

Podemos considerar en este aspecto que existen dos tipos diferentes de patrocinios, por un lado estarían aquellos patrocinadores que no tienen nada que ver con el producto, como por ejemplo si "The Simpson" lo patrocina la Central lechera Asturiana. En el otro extremo encontramos los productos relacionados, como puede ser el caso de que el patrocinador de "Dragon Ball" sea Bandai, la cual comercializa los muñecos de la serie, y sean precisamente estos muñecos los que patrocinen el producto. Obviamente, estos muñecos tienen un interés en el mantenimiento de la serie, y en el éxito del misma, ya que a más éxito de la serie, más éxito de los muñecos ${ }^{44}$.

En el caso del cine, este patrocinio viene bien, ante todo en los 90', como preocupación de una empresa por el cine español de animación, que en estos años se empezaba a estabilizar. El caso del cine español en general con la empresa Mahou, sería un ejemplo de este tipo.

En relación a este aspecto, tenemos por ejemplo la práctica que realiza Mcdonald, la cual ofrece una serie de juguetes de diversos productos animados. Esto coincide en el tiempo con la proyección de esta obra, lo que produce en un reclamo y una retroalimentación publicitaria entre ambos productos. Uno puede ir a Mcdonald y encontrará la publicidad de la película, al mismo tiempo si uno ve la película, conocerá la oferta del Mcdonald. Además ambos productos se suelen patrocinar de forma independiente, pero en el mismo tiempo, por lo que se estaría hablando de una doble publicidad.

${ }^{44}$ Teóricamente. 
REVISTA DE LA SEECI.



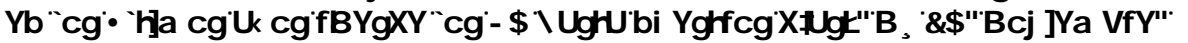

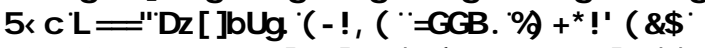

' 2, पKW

\subsubsection{Product Placement}

Luego tenemos el "product placement", que es colocar el producto de un patrocinador dentro de la producción. Esto es más habitual en las producciones en imagen real, pero la animación no está exenta de este tipo de publicidad.

\subsubsection{Merchaidasing}

El merchaidasing de productos relacionados con el mundo de la animación ya está presente desde hace bastante tiempo, ya mencione que Disney casi desde los inicios de la compañía lo realizaba, y en los $80^{\prime}$ el relevo lo toman las series televisivas de éxito. Ahora esta tendencia se mantiene, pero ante la multiplicación de productos animados, los juguetes, cromos, etc. también se han multiplicado, y con ello la publicidad relacionada a los mismos. Es conveniente no obstante señalar que normalmente se trata de productos dirigidos a los niños.

En el caso de los adolescentes, la tendencia es diferente. Normalmente los productos que reclaman están relacionados con series y productos muy diversos, como pueden ser los japoneses o del comic americano. Estos productos se venden en tiendas más especializadas, y estas normalmente recurren a internet para promocionar sus productos.

\subsubsection{Otras formas}

Para terminar estas nuevas formas de publicidad, tenemos que hablar de la producción de diversos productos para promocionar el producto. Un ejemplo de esto sería "Pokemon", serie que se creó de forma posterior al videojuego. En España el videojuego llegó con un cierto retraso, por lo que el estreno de 
REVISTA DE LA SEECI.

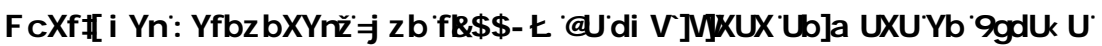

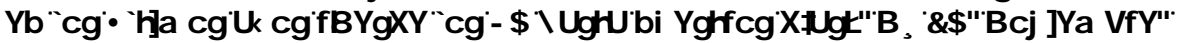

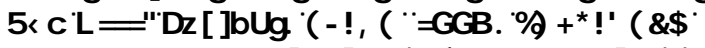

' 2, पKMB

ambos productos es casi simultáneo. De todos modos, esta serie es un buen ejemplo, ya que a medida que se sacan nuevas versiones del videojuego, con nuevos personajes, estos se van introduciendo en el mundo de "Pokemon" para promocionarlos. A estos sumemos las numerosas películas, que sirven tanto para promocionar la serie como el videojuego.

Por consiguiente, esto sería un ejemplo de producción para promocionar un producto. Pero también se puede realizar una serie de productos para regalar a las televisiones, a fin de obtener espacios publicitarios en la cadena. Esta modalidad sería más un trueque de servicios. Hay que mencionar que la animación puede ser un producto muy dado a este tipo de aspectos.

\subsubsection{Internet}

Ya saliéndonos un poco de los medios tradicionales, en internet podemos encontrar diversos productos publicitarios relacionados con técnicas de animación, como pueden ser los múltiples clips animados, los cuales podemos encontrar en cualquier página. Además de los anuncios propios de productos animados, como por ejemplo los anuncios de productos relacionados con el mundo del comic, como he mencionado previamente.

Actualmente, internet se está mostrando como una gran alternativa a la televisión, así como un nuevo medio para la publicidad. Dado que aún están muy cercanos en el tiempo, existen grandes lagunas, por lo que será preciso esperar un poco de tiempo para poder realizar estudios serios del asunto. 
REVISTA DE LA SEECI.

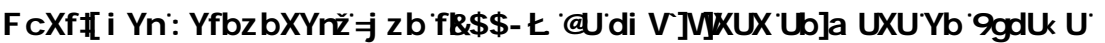

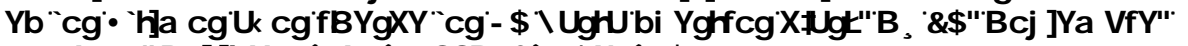

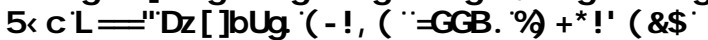



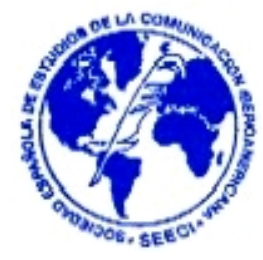

\subsection{Autopromocionales, cortinillas, etc.}

Un aspecto que no he mencionado por el momento en el trabajo, son los promocionales de las televisiones, y sus cortinillas, sobretodo estas últimas, donde la animación ha jugado un gran papel. Con el inicio de la década, en España llega la pluralidad televisiva, lo que ayuda a fragmentar la audiencia. Posteriormente con internet, la televisión por cable, satélite, etc. esto se radicalizará. Pero al aparecer nuevos soportes, también aparecen nuevas demandas de este tipo de productos.

Las cortinillas son un medio que tiene la televisión para separar sectores de programación, así como para promocionarse ella misma. Posiblemente, las más destacables para la animación sean las relacionadas con Canal +. 0 más recientemente el canal Fox, el cual ha recurrido por ejemplo a la imagen de Homer cayéndose del sofá, intercalo con el logotipo de Fox. Esta última juega con el metalenguaje, y tira del éxito de una serie consagrada.

En los últimos tiempos hemos podido ver como los logotipos de las televisiones se iban adaptando a ciertos estrenos de productos de cierto renombre, produciéndose una cierta retroalimentación entre los promocionales de unos y otros. Antena 3 recientemente lo ha realizado para promocionar la película de producción propia "Planet 51".

Por último, mencionar los promocionales de productos de animación, que en el caso español recurre a imágenes del propio producto para crearse, normalmente adquiriendo la forma de trailler. Existen diversas formas de realizarse, desde lo más tradicional, a las campañas teaser. En otros mercados es común que estos promocionales no recurran solamente a imágenes enlatadas, sino que se pueden crear exclusivamente para el anuncio, como por ejemplo el inicio del trailler de "The Simpson: La película". 
REVISTA DE LA SEECI.

5RGH XHD HQi QGH

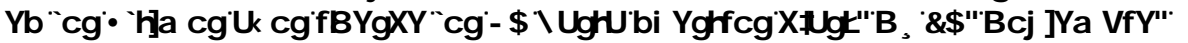

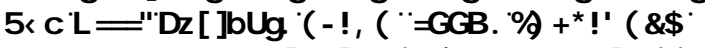

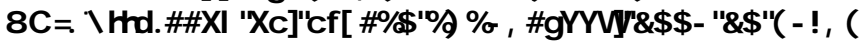

Estos últimos aspectos requieren un análisis más en profundidad para poder tener una visión clara de los mismos. Realizarlo podría suponer alejarnos de la concepción inicial del trabajo, que simplemente planteaba mostrar de forma superficial la relación entre ambos universos. Por lo que me limitaré a una mención.

\section{Conclusiones}

Hablar de los años 90' en animación, significa indudablemente hablar de una renovación en todos los sentidos. Una renovación de mensaje, Disney cambia de director y esto se refleja en la animación, a esto sumemos las nuevas productoras que empiezan su andadura en estos años y que proporcionan una nueva visión de la animación. Sin olvidarnos por supuesto, de las series de éxito, que demuestran que la animación no es un producto exclusivo para niños.

Por consiguiente, tenemos que hablar también, del fin de la consideración que la animación es un producto exclusivo de niños. Este factor ayudará a la reincorporación de la animación en publicidad. Pero para esta reincorporación tenemos necesitamos que la técnica evolucione.

Hablar de los 90', significa hablar indudablemente de Pixar y su "Toy Story". La animación por ordenador se empieza a desarrollar ya en los 80', pero será en estos años cuando se estabilice y empiece su gran desarrollo, desbancando a la animación por dibujos animados. La mejora de la técnica, también nos obliga a mencionar el realismo estético que se obtiene, y el gran éxito en cuanto a efecto que adquiere la animación. 
REVISTA DE LA SEECI.

Rodríguez Fernández, Iván (2009): La publicidad animada en España en los últimos años (Desde los 90 hasta nuestros días). № 20. Noviembre. Año XIII. Páginas: 49-84 ISSN: 1576-3420

DOI: http://dx.doi.org/10.15198/seeci.2009.20.49-84

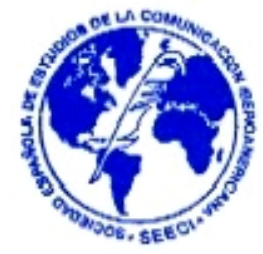

Precisamente, como efecto dentro de los spot podemos encontrar innumerables ejemplos actualmente. Podemos decir que la animación como efecto, para la mejora del spot, está en su momento álgido actualmente.

Pero si unimos técnica, cambio en el mensaje y la concepción, nos conduce a hablar de realismo en la animación por ordenador. Lo que permite a ciertos personajes animados adueñarse nuevamente de los spot publicitarios.

Para ello, tendremos que asistir a la desaparición de la concepción de realidad que en los 60' había impuesto la televisión.

Si hablamos de televisión, los 90' significa para España la llegada de las televisiones privadas. Y posteriormente llegará el inicio del fin de la televisión como medio predominante. Sumemos a esto la llegada del cable, el satélite y por supuesto internet. Todo ello contribuirá a la fragmentación de la sociedad en grupos cada vez más pequeños.

Al publicista le resulta más difícil llegar al consumidor, por lo que empiezan a aparecer nuevas formas de publicidad que ayudan a acercar el producto a sus clientes. La fragmentación, permite que los productos se dirijan de una forma más específica a un sector del público concreto. Por ejemplo, el público infantil tiene un referente en Clan Tv, entre otros, por lo que el empresario sabe que en este tipo de lugares puede encontrar a su target.

De todos modos, el espectador ya conoce el mundo publicitario, ya no le es nuevo, por lo que el publicista necesita idear nuevas formas para llamar la atención del consumidor, para inducirle a consumir sus productos.

En este periodo, cobra fuerza la publicidad de imagen corporativa, por la cual a los productos $\mathrm{y} / 0$ empresas se las cubre con una personalidad, principios, etc. 
REVISTA DE LA SEECI.

Rodríguez Fernández, Iván (2009): La publicidad animada en España en los últimos años (Desde los 90 hasta nuestros días). $\mathbf{N}^{\circ} \mathbf{2 0}$. Noviembre.

Año XIII. Páginas: 49-84 ISSN: 1576-3420

DOI: http://dx.doi.org/10.15198/seeci.2009.20.49-84

Así, además de la publicidad tradicional se recurre a nuevas formas que contribuyan a crear esa imagen, como el patrocinio de diversos eventos.

Centrándonos en los spots, es importante señalar que frente a la imagen atractiva de la etapa anterior, ahora se desarrolla una imagen simbólica. La imagen se recarga de significado, obviamente juega con el saber del espectador, el cual tiene que reconocer los códigos que en ella se presenta.

Además, sumemos que cada vez la publicidad es más cercana a los consumidores, es más común. El consumidor ya conoce que es la publicidad, por lo que esta se va acercando al consumidor. Otro tipo de relaciones comerciales como las relaciones públicas, o la promoción en el lugar de venta, acentúan este acercamiento del mundo publicitario al consumidor.

Ya partiendo de ese conocimiento del espectador, la publicidad se llena de referencias, en su mayoría cinematográficas, así como de un metalenguaje.

El tono de los anuncios de estos años será un tono humorístico, relajado. Esto va en consonancia con las producciones animadas de estos años en occidente, donde existe un predominio de la animación de corte humorístico.

Por último, mencionar algunas nuevas formas publicitarias con las que se puede relacionar el sector de la animación.

Por un lado tenemos la promoción, tanto a través de productos relacionados con el que se promociona, como productos totalmente independientes.

Por otro lado, estaría el "product placement" que consiste en colocar dentro de la obra de animación, referencias hacia una marca o producto.

Luego tenemos casos en los que una empresa realiza un producto de animación, ya sea para promocionar su producto, o para obtener ventajas publicitarias en el canal. 
REVISTA DE LA SEECI.

Rodríguez Fernández, Iván (2009): La publicidad animada en España en los últimos años (Desde los 90 hasta nuestros días). $\mathbf{N}^{\circ} \mathbf{2 0}$. Noviembre.

Año XIII. Páginas: 49-84 ISSN: 1576-3420

DOI: http://dx.doi.org/10.15198/seeci.2009.20.49-84

A esto tenemos que sumar el merchandaising, que se sigue dando en este periodo, aunque de una forma más acusada, en la medida en que existen más productos. También los traillers y los autopromocionales se mantienen en esta época.

En relación con las televisiones, mencionar antes de terminar las cortinillas, autopromocionales, etc. ya que en muchos casos para su realización se recurrirá a la animación.

\section{Bibliografía}

ALBERTI, Walter (1957): // cinema di animazione 1832 - 1956. Edizioni Radio. Torino. Italia.

BENDAZZI, Giannalberto (2001): "I continenti del cinema d'animazione" en BENDAZZI, Giannalberto (2000): "Storia del cinema mondiale IV; Americhe, Africa, Asia, Oceania" en La cinematografia nazionali de SPINA, Mario (Redactor), Einaudi. Torino.

BENDAZZI, Giannalberto (1999): “L'animazione” en BENDAZZI, Giannalberto, Storia del cinema mondiale: Gli Statu Uniti // Primer tomo en EINAUDI Giulio (Editore) S.P.A.. Torino.

BENDAZZI, Giannalberto (1999): "L'animazione europea, ieri e oggi" en BENDAZZI, Giannalberto, Storia del cinema mondiale: L'Europa 1. Miti, luoghi, divi en EINAUDi Giulio (Editore) S.P.A.. Torino.

BENDAZZI, Giannalberto (2003): Cartoons, 110 años de cine de animación. Ocho y medio. Madrid. 
REVISTA DE LA SEECI.

Rodríguez Fernández, Iván (2009): La publicidad animada en España en los últimos años (Desde los 90 hasta nuestros días). № 20. Noviembre.

Año XIII. Páginas: 49-84 ISSN: 1576-3420

DOI: http://dx.doi.org/10.15198/seeci.2009.20.49-84

BUDASSI, Enzo (1972): Arte e tecnica del film di animazione. Edizioni Bizzarri. Roma.

BUDASSI, Enzo (1972): Arte e tecnica del film di animazione. Edizioni Bizzarri. Roma.

CÁCERES, Germán (1999): Entre dibujos, marionetas y pixeles. La Crujía ediciones. Ciudad autónoma de Buenos Aires.

CHOMSKY, N.; RAMONET, I. (1997): Cómo nos venden la moto. Icara. Barcelona.

CULHANE, John (1983): Walt Disney's FANTASIA. Abradale Press / Harry N. Abrams, Inc. Publishers. New York.

CRAFTON, Donald (2007): "Emile Cohl, acteur de cinéma d'animation" en CRAFTON, Donald CinémAnimations. Condè-sur-noireau.

DELGADO, Pedro Eugenio (2006): El cine de animación. Colección Imágenes Número 28 Ediciones J C,. Madrid.

EGUIZÁBAL MAZA, Raúl (1998): Historia de la publicidad. Editorial Eresma and Celeste ediciones. Madrid.

FONTE, Jorge (2004): Todo empezó con un ratón. El fantástico mundo de los cortos Disney. T\&B Editores.; Madrid. 2004.

GÉNIN, Bernard (2005): // cinema d'animazione: Dai disegni animati alle immagini di sintesi, dalla matita al computer, pro e contro Disney, Europa Giappone: il cartoné animato oggi. Lindau s.r.l.; Torino.

HANG LI, Chi; PATMORE, Chris y SCOTT-BARON, Hayden (2008): Animación Manga. Manual de técnicas de anime. Crear fascinantes animaciones con lápices, pinceles y píxeles. Editorial Acanto. Barcelona. 
REVISTA DE LA SEECI.

Rodríguez Fernández, Iván (2009): La publicidad animada en España en los últimos años (Desde los 90 hasta nuestros días). $\mathbf{N}^{\circ} \mathbf{2 0}$. Noviembre.

Año XIII. Páginas: 49-84 ISSN: 1576-3420

DOI: http://dx.doi.org/10.15198/seeci.2009.20.49-84

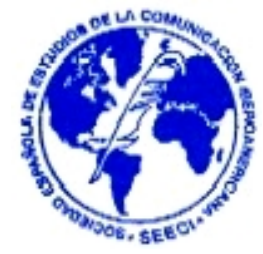

HOPKINS, John (2004): Shrek, From the Swamp to the Screen. Harry N. Abrams, Inc. New York. 2004.

JETRO, G. (2004): "Continua la difusión global de la animación japonesa". Disponible en: www.jetro.go.jp/spain/mercado/tendencia/2004_07_anime.html Consultado el: 12/12/08

KERN, Adam L. (2006): Manga, from the Floating world, Comicbook Culture ans the kibyôshi of Edo Japan. Harvard University Asia Center. Cambrudge (Massachusetts).

LANE, Aandy (2003): Aardman presents: Creating Creature Comforts: The award - winning animation brought ti life from the makers of "Chiken Run" and "Wallace and Gromit". Aadman Animations Ltd. Y Pan Macmillan. Londres.

LORD, Peter; SIBLEY, Brian (2004): Cracking animation. Thames and Hudson; Londres.

MACWILLIAMS, Mark W. (Director) (2008): Japanese visual cultura: Explorations in the world of manga and anime. M.E. Sharpe, Inc.. New York.

MARKESTEIN; Donald D. (2009) "Mickey Mouse" Art @ Walt Disney Co.. Disponible en www.toonopedia.com/mickey.htm. Consultado el 06/02/09.

MARTINELLI ARLOTTI, Paola (2004): In moto perpetuo: L'animazione in 3D nel cinema e nella televisione dalla fine del XIX secolo alla fine del XX. Corporativa Libraria Universitaria Editrice Bologna. Bolonia.

MARTÍNEZ BARNUEVO, María Luisa (2005): El largometraje español: análisis y evaluación. Ediciones y publicaciones autor S.R.L.. Madrid.

MARTOS, Eladi (2005): La pareja feliz; Baca i Garriga: La animación como un juego. Colección Animadrid. Madrid. 
REVISTA DE LA SEECI.

Rodríguez Fernández, Iván (2009): La publicidad animada en España en los últimos años (Desde los 90 hasta nuestros días). $\mathbf{N}^{\circ} \mathbf{2 0}$. Noviembre.

Año XIII. Páginas: 49-84 ISSN: 1576-3420

DOI: http://dx.doi.org/10.15198/seeci.2009.20.49-84

MUCCHIELLI, Roger (1977): Psicología de la publicidad y de la propaganda: conocimiento del problema, aplicaciones prácticas. Ediciones mensajero. Bilbao.

PAIK, Karen (2007): The art of Ratatouille. Disney Enterprises. Inc/ Pixar.. Chronicle Books LLC; San Francisco.

PRATKANIS, Aanthony y ARONSON, Elliot (1994): La era de la propaganda: Uso y abuso de la persuasión. Ediciones Paidós. Barcelona.

QUINTEROS, Nicolás (2002): Max Fleischer: Dibujando el futuro. La linterna mágica.

VV.AA. (2007): Fantasmagoría; Dibujo en movimiento. Fundación ICO.

VV.AA. (2008): Cine de animación japonés. Semana de cine fantástico y de terror de San Sebastián. San Sebastián.

YÉBENES, Pilar (2002): Cine de animación es España. Ariel Cine. Barcelona.

WEINRICHTER, Antonio (2002): Pantalla amarilla: El cine japonés. T and B editores. Madrid.

WEISHAR, Peter (2004): Moving Pixels; Blockbuster Animation, Digital Art and 3D Modelling Today. Tames and Hudson Ltd.. Londres.

WELLS, Paúl (Editor) (2006): Halas and Batchelor Cartoons. An animated history. Southback Publishing. Londres.

WELLS, Paul (2007): Fundamentos de la animación. Parramón. Singapur. 